\title{
AVALIAÇÃO DA QUALIDADE DA ÁGUA EM ASSENTAMENTOS RURAIS DA REGIÃO DE UBERLÂNDIA/MG
}

\author{
Sueli Moura Bertolino - suelibertolino@iciag.ufu.br \\ Universidade Federal de Uberlândia
}

Camila Marques Alves Aguiar - camila.aguiiar@hotmail.com

Universidade Federal de Uberlândia

Arthur Cunha Carvalho - arthurcarvalhou@gmail.com

Universidade Federal de Uberlândia 


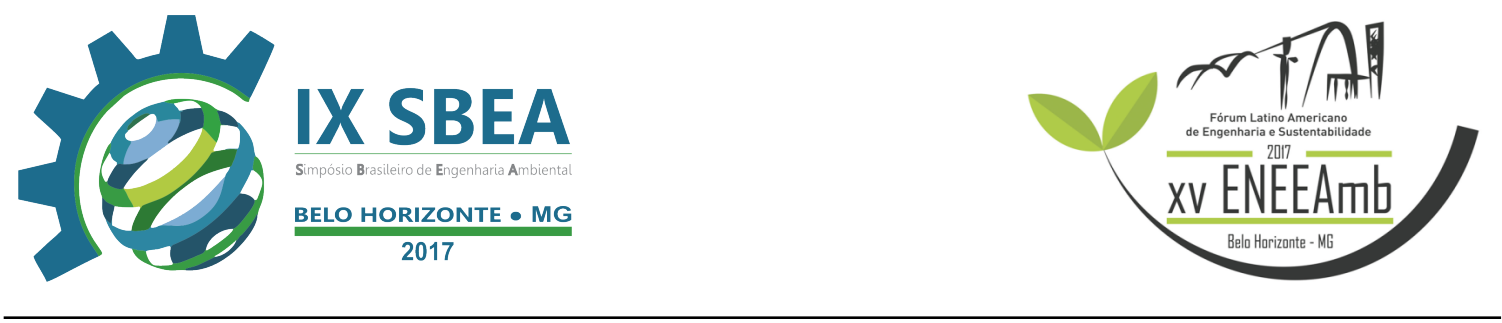

\section{RESUMO}

O objetivo deste estudo foi analisar as propriedades físico-químico da água para fins de consumo, irrigação e dessedentação de animais no Assentamento Emiliano Zapata e no Assentamento Nova Tangará, utilizando o equipamento multiparâmetro HANNA para análise de temperatura, sólidos totais, turbidez, condutividade elétrica, $\mathrm{pH}$, oxigênio dissolvido e potencial de oxirredução comparando com os valores estabelecidos pela Resolução no 357 do CONAMA de 2005. Foram coletadas amostras em seis pontos de cada assentamento, nos principais pontos de consumo pela comunidade, através das análises foi possível concluir que para os parâmetros físico-químicos analisados apresentaram-se de acordo com a norma.

Palavras-chave: Qualidade de água, Nova Tangará, Emiliano Zapata.

\section{INTRODUÇÃO/OBJETIVO}

A discussão, para a formulação de um modelo de reforma agrária diferenciando social e ambientalmente, tem-se aprofundado nos últimos anos. Nessa perspectiva, discute-se a implantação de um modelo menos dependente de insumos externos, mais autônomo economicamente e menos impactante ao meio ambiente (CANUTO, ÁVILA E CAMARGO, 2013).

Entretanto, a carência de infraestrutura básica oferecida à vida no campo aliada a um histórico violento de luta pela terra, a dependência do Estado diante da economia e as divergências internas ao movimento social parecem agravar a situação do pequeno proprietário de terra no Brasil (MARTINS, 2003).

Logo, a partir de meados dos anos 80 , com o aumento do número de projetos de assentamentos rurais, o interesse de compreender o funcionamento dessas novas unidades produtivas cresceu significativamente. Porém, os impactos que tais atividades agrárias geram têm sido pouco trabalhados.

Tradicionalmente, existe grande polêmica quanto à segregação de grandes propriedades de terra em mosaicos menores devido a sobrecarga gerada nos meios físicos, biológicos e socioeconômicos, repercutindo nos recursos naturais e na própria 


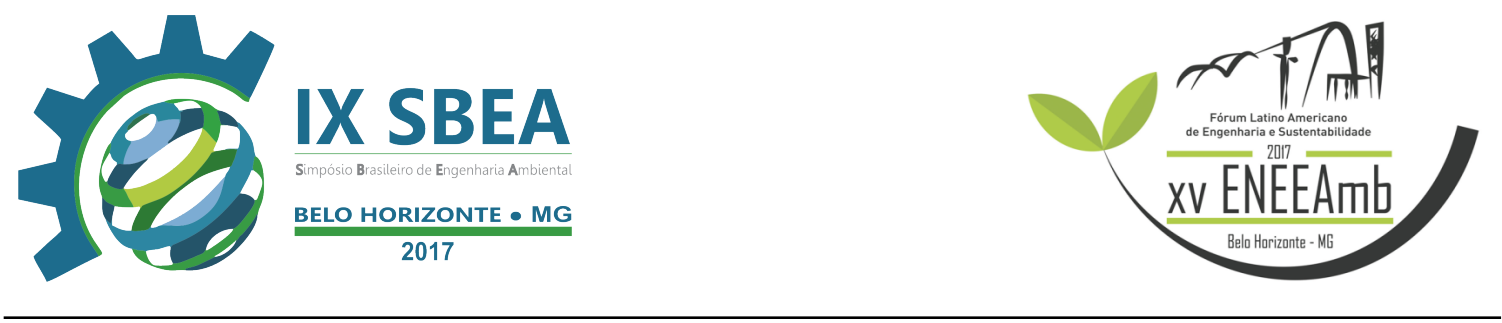

vida do produtor familiar. Portanto, questões como contaminação ou exploração excessiva dos recursos hídricos, escassez e poluição das águas, baixa qualidade da moradia, ausência de saneamento básico, degradação dos solos agricultáveis e destinação dos resíduos sólidos são de suma importância à melhoria da qualidade de vida no campo.

Nesse sentido, o Conselho Nacional do Meio Ambiente (CONAMA) sancionou a Resolução N 387 de 27 de dezembro de 2006, ao qual estabelece diretrizes e procedimentos de controle e gestão ambiental para orientar e disciplinar o uso e a exploração dos recursos naturais, de modo a assegurar a proteção do meio ambiente nos Projetos de Assentamentos de Reforma Agrária.

Diante de uma evidente abordagem superficial a respeito da qualidade do saneamento ambiental nos assentamentos rurais brasileiros, vê-se necessário aprofundar estudos e análises que ressaltam as dificuldades de implantar ações que integrem processos participativos e desenvolvimento sustentável.

Dessa forma, tendo como parâmetro a Lei $\mathrm{N}^{0} 11.445$ de 5 de janeiro de 2007, ao qual estabelece diretrizes para a efetivação de um sistema de saneamento básico, e o Manual de Saneamento da Fundação Nacional de Saúde (FUNASA), define-se saneamento como sendo ações socioeconômicas que visam atingir níveis de salubridade ambiental através do abastecimento de água potável, coleta e disposição sanitária de resíduos sólidos, líquidos e gasosos, promoção, controle de doenças transmissíveis, e demais serviços e obras especializadas, com a finalidade de promover melhores condições de vida urbana e rural.

Segundo Stukel (1990), surtos de doenças de veiculação hídrica no meio rural possuem altos índices de ocorrência, principalmente em função da contaminação bacteriana da água que, muitas vezes, são captadas sem nenhuma preocupação sanitária e com estrutura inadequada, próximos à fossas e áreas de pastagens ocupadas por animais.

Percebe-se, portanto, que a população rural vive uma escassez de recursos financeiros, bem como acesso a tecnologias desapropriadas para seu modo de vida, 


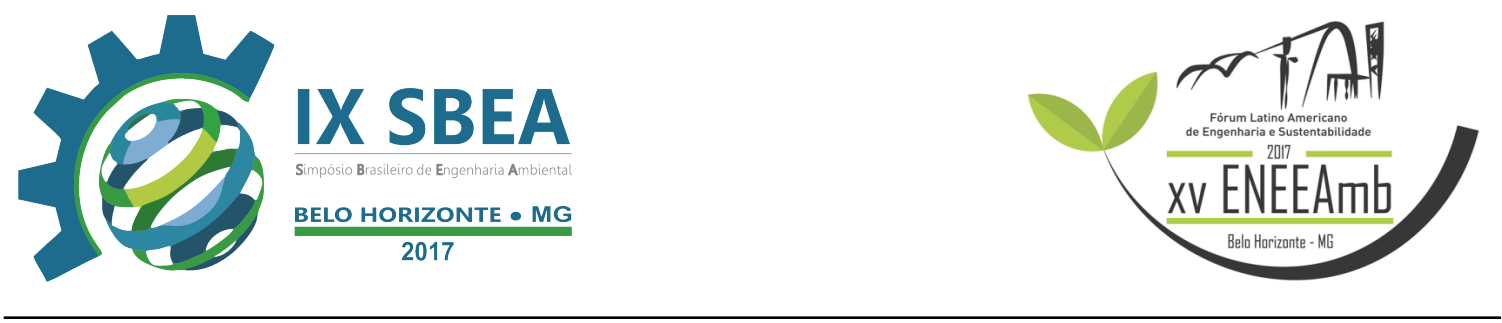

fatores que dificultam a busca por novas e eficientes formas de manutenção dos recursos hídricos dentro dos assentamentos rurais. (ALMEIDA, 2007).

Portanto, o desenvolvimento de assentamentos sustentáveis focados em práticas agroecológicas preocupadas com a gestão dos recursos hídricos, são desafios a serem superados a fim de tornar essas áreas modelos de conservação dos recursos naturais e da biodiversidade, além de promover a melhoria das condições de vida das famílias rurais.

\section{METODOLOGIA}

As análise dos parâmetros físico-químicos de qualidade da água, no Assentamento Emiliano Zapata e Nova Tangará, foram realizadas através do multiparâmetro HANNA HI9829 in loco onde serão analisados os seguintes parâmetros físico-químicos: potencial de hidrogênio $(\mathrm{pH})$, oxigênio dissolvido (OD), condutividade, sólidos totais, turbidez e temperatura. Assim, será possível identificar a situação real da água, estabelecendo uma comparação com a legislação vigente no país. Foram analisados 6 pontos diferentes nas duas comunidades que são utilizados para consumo e dessedentação de animais.

No assentamento Emiliano Zapata, foram analisados os pontos 1, 2, 3, 4, 5, e 6 presentes na Figura (1). 

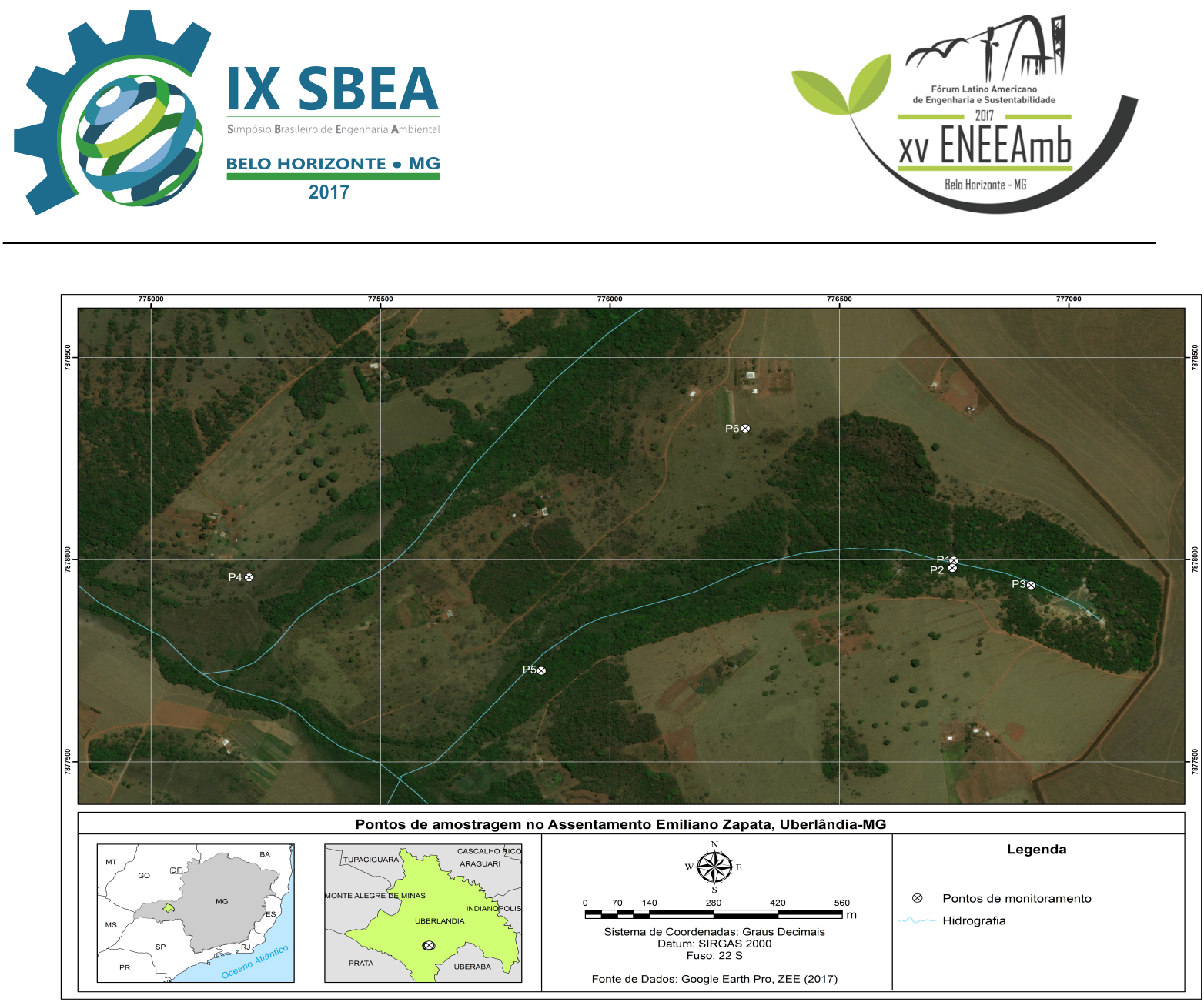

Figura 1- Pontos de amostragem no Assentamento Emiliano Zapata.

Fonte: Ruiz (2017).

No assentamento Nova Tangará, foram selecionados os pontos 1, 2, 3, 4, 5 e 6 para análise considerando que estes são fonte de abastecimento essenciais para a comunidade. Na figura (2), é possível observar a localização dos pontos de amostragem. 

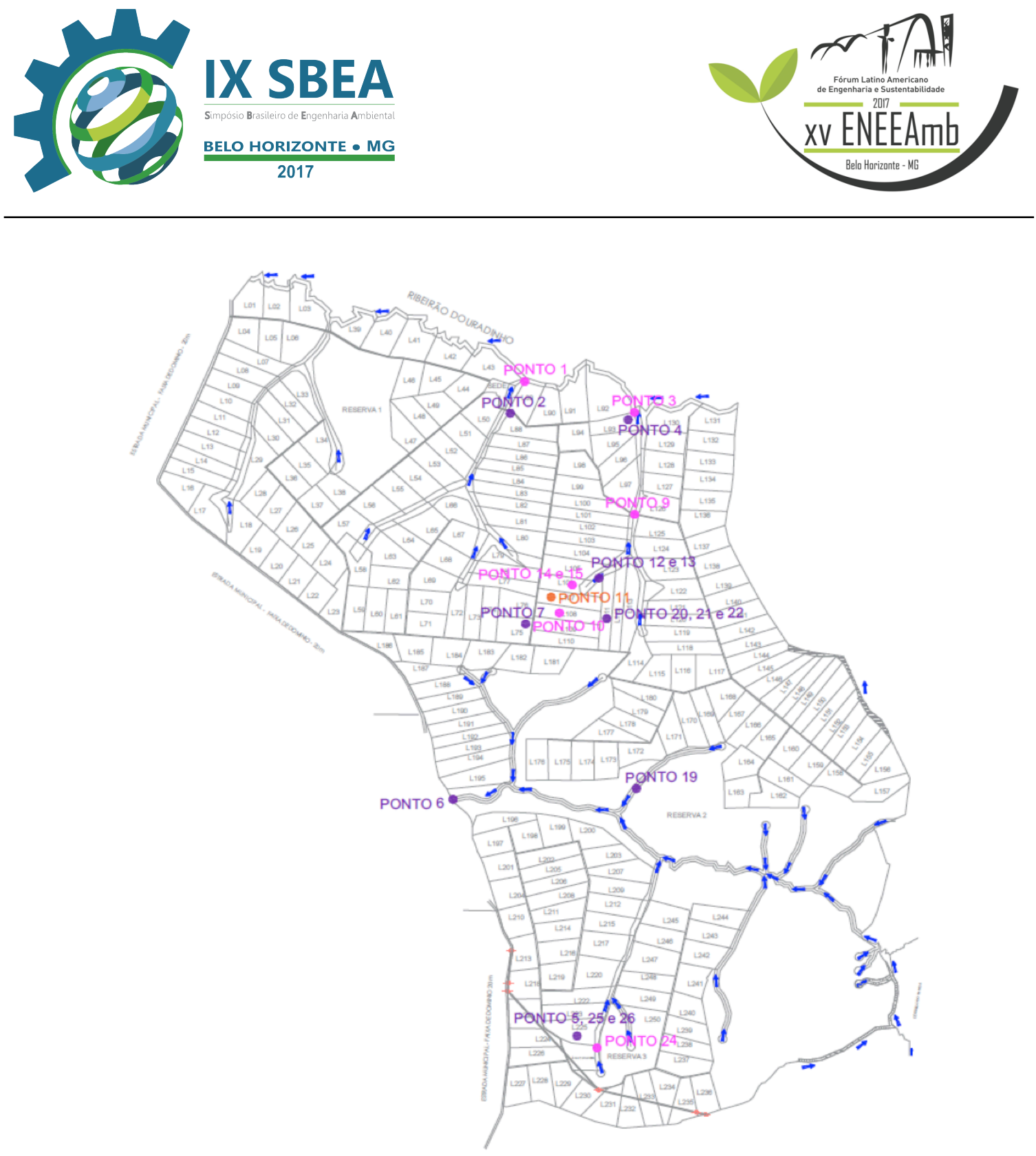

Figura 2 - Pontos de amostragem no Assentamento Nova Tangará.

Fonte: Autores (2017)

A legislação vigente que define os limites de concentração dos parâmetros de qualidade da água é a Resolução CONAMA no 357 de 2005 e a Portaria do Ministério da Saúde no 2.914 de 2011. Estes valores foram utilizados para comparação dos resultados obtidos pelo estudo dos assentamentos e estão representados na Tabela 1.

Tabela 1 - Valores máximos de referência presentes na legislação. 


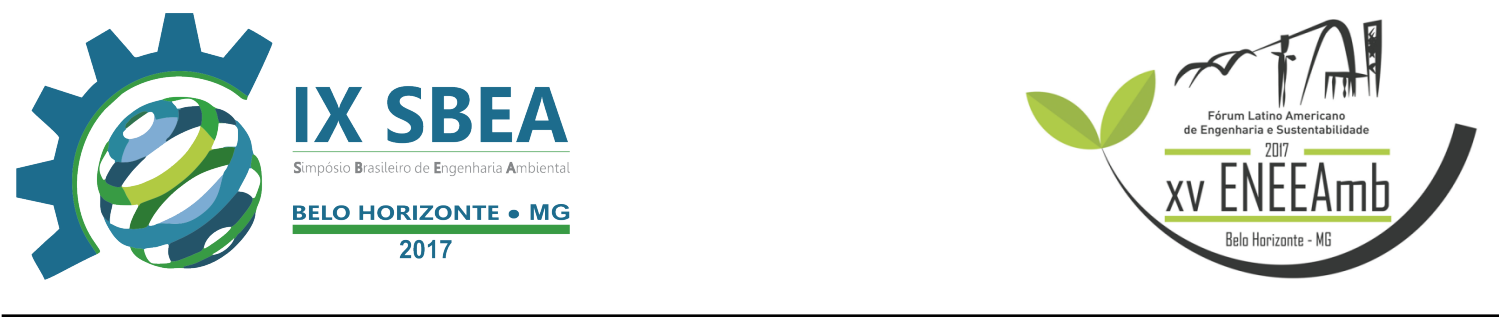

\begin{tabular}{|c|c|c|c|c|c|}
\hline \multicolumn{6}{|c|}{ Valores máximos de referência } \\
\hline \multirow{2}{*}{ Parâmetro } & \multirow{2}{*}{ Unidade } & \multicolumn{3}{|c|}{ CONAMA 357/2005 } & \multirow{2}{*}{$\begin{array}{c}\text { Portaria No } \\
2914 / 2011\end{array}$} \\
\hline & & Classe 1 & Classe 2 & Classe 3 & \\
\hline$\overline{\mathrm{pH}}$ & - & 6,0 a 9,0 & 6,0 a 9,0 & 6,0 a 9,0 & 6,0 a 9,5 \\
\hline $\begin{array}{c}\text { Condutivida } \\
\text { de }\end{array}$ & $\mu \mathrm{s} / \mathrm{cm}$ & - & - & - & - \\
\hline Turbidez & UNT & $\leq 40$ & $\leq 100$ & $\leq 100$ & $\leq 1$ \\
\hline Cor & $\mathrm{mgPt} / \mathrm{L}$ & $\leq 75$ & $\leq 75$ (ap.) & $\leq 75$ (ap.) & $\leq 15$ (ap.) \\
\hline $\begin{array}{c}\text { Temperatur } \\
\mathrm{a}\end{array}$ & ${ }^{\circ} \mathrm{C}$ & - & - & - & - \\
\hline Cloretos & $\mathrm{mg} / \mathrm{L}$ & 250 & 250 & 250 & 250 \\
\hline Dureza total & $\begin{array}{c}\mathrm{mgCaCO} 3 / \\
\mathrm{L}\end{array}$ & - & - & - & 500 \\
\hline Ferro & $\mathrm{mg} / \mathrm{L}$ & $\overline{0,3}$ & 0,3 & 5 & 0,3 \\
\hline Manganês & $\mathrm{mg} / \mathrm{L}$ & $\overline{0,1}$ & 0,1 & $\overline{0,5}$ & 0,1 \\
\hline Fósforo & $\mathrm{mg} / \mathrm{L}$ & 0,02 & 0,03 & 0,05 & - \\
\hline $\begin{array}{l}\text { Sólidos } \\
\text { totais }\end{array}$ & $\mathrm{mg} / \mathrm{L}$ & 500 & 500 & 500 & 1000 \\
\hline$\overline{\mathrm{DQO}}$ & $\mathrm{mgO} 2 / \mathrm{L}$ & - & - & - & - \\
\hline$\overline{\mathrm{DBO}}$ & $\mathrm{mgO} 2 / \mathrm{L}$ & $\leq 3$ & $\leq 5$ & $\leq 10$ & - \\
\hline$\overline{O D}$ & $\mathrm{mgO} 2 / \mathrm{L}$ & $\geq 5$ & $\geq 5$ & $\geq 4$ & - \\
\hline
\end{tabular}

Fonte: adaptação Resolução CONAMA 357/2007.

\subsection{Oxigênio dissolvido (OD)}

O método utilizado para o cálculo é o de Winkler, que visa a adição de uma solução de manganês reduzido $\left(\mathrm{Mn}^{2+}\right)$ seguida de uma solução contendo uma base, íons iodeto e azida $\left(\mathrm{N}_{3}^{-}\right)$, resultando na produção de um precipitado branco. A presença desse precipitado evidência a ausência de OD.

\subsection{Potencial hidrogeniônico $(\mathbf{p H})$}

Para determinar o pH, o método padrão é a utilização do eletrodo de hidrogênio. Existe também uma série de indicadores que foram calibrados contra o eletrodo para determinar suas características de cor em diferentes níveis de $\mathrm{pH}$, permitindo assim estimar o $\mathrm{pH}$ por colorimetria.

\subsection{Temperatura da água}




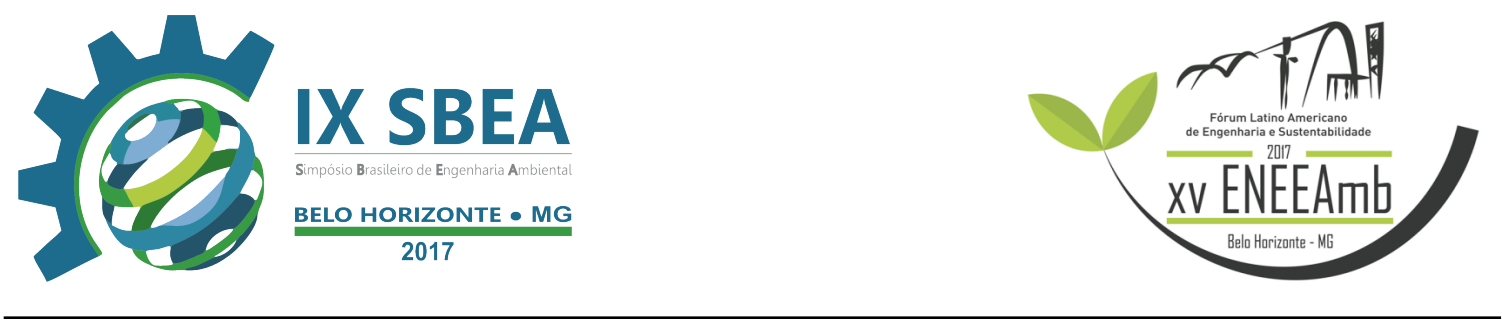

A temperatura influência vários parâmetros físico-químicos da água e os organismos aquáticos são afetados se estiverem fora de seus limites de tolerância térmica, causando impactos sobre seu crescimento e reprodução. A temperatura é medida através de um termômetro.

\subsection{Turbidez}

A turbidez é determinada pelo princípio da nefelometria, em célula fotoelétrica. Mede-se a quantidade de luz que atravessa a amostra, acondicionada dentro de uma cubeta incolor e transparente.

\subsection{Sólidos Totais}

Uma amostra homogênea é evaporada e previamente pesada e seca a uma temperatura de 103 a $105^{\circ} \mathrm{C}$. A amostra pode ser filtrada em filtro seco e pesada, antes da evaporação.

\section{RESULTADOS E DISCUSSÃO}

No Assentamento Emiliano Zapata, foram analisados parâmetros físicoquímicos presentes na tabela 2 abaixo. De acordo com a classificação das águas doces e seus respectivos usos estabelecidos pela resolução CONAMA 357/2005, as amostras se enquadram na classe 1.

Tabela 2 - Análise dos valores obtidos no Assentamento Emiliano Zapata com base na Resolução CONAMA 357.

\begin{tabular}{|c|c|c|c|c|c|c|c|}
\hline Parâmetros & $\begin{array}{c}\text { Ponto } \\
1\end{array}$ & $\begin{array}{c}\text { Ponto } \\
2\end{array}$ & $\begin{array}{c}\text { Ponto } \\
3\end{array}$ & $\begin{array}{c}\text { Ponto } \\
4\end{array}$ & $\begin{array}{c}\text { Ponto } \\
5\end{array}$ & $\begin{array}{c}\text { Ponto } \\
6\end{array}$ & $\begin{array}{c}\text { Valores } \\
\text { estabelecidos pela } \\
\text { CONAMA } \\
357 / 2005\end{array}$ \\
\hline $\mathrm{pH}$ & 5,46 & 5,05 & 7,54 & 5,76 & 5 & 6,26 & $6,0-9,0$ \\
\hline $\begin{array}{c}\text { Oxigênio } \\
\text { Dissolvido } \\
(\mathrm{mg} / \mathrm{L})\end{array}$ & 35 & 68 & 63,9 & 76 & 80 & 69 & $\geq 6$ \\
\hline Eh(mV) & 2,7 & 5,45 & 5,16 & 6,47 & 6,4 & 5,54 & - \\
\hline $\begin{array}{c}\text { Condutividade } \\
(\mu \text { S/cm) }\end{array}$ & 22 & 3 & 76 & 19 & 10 & 120 & - \\
\hline SDT $(\mathrm{ppm})$ & 11 & 2 & 38 & 9 & 5 & 60 & $\leq 500$ \\
\hline
\end{tabular}




\begin{tabular}{|c|c|c|c|c|c|c|c|}
$\begin{array}{c}\text { Turbidez } \\
\text { (UNT) }\end{array}$ & - & - & 22 & - & 13 & 25 & $\leq 40$ \\
\hline Temperatura & 24 & 22 & 22 & 22 & 23,35 & 22,3 & - \\
\hline
\end{tabular}

Tabela 3 - Análise dos valores obtidos no Assentamento Nova Tangará com base na Resolução CONAMA 357.

\begin{tabular}{|c|c|c|c|c|c|c|c|}
\hline Parâmetros & $\begin{array}{c}\text { Ponto } \\
1\end{array}$ & Ponto 2 & $\begin{array}{c}\text { Ponto } \\
3\end{array}$ & Ponto 4 & Ponto 5 & $\begin{array}{c}\text { Ponto } \\
6\end{array}$ & $\begin{array}{c}\text { Valores } \\
\text { estabelecidos } \\
\text { pela } \\
\text { CONAMA } \\
357 / 2005\end{array}$ \\
\hline $\mathrm{pH}$ & 5,43 & 7,8 & 7,54 & 5,76 & 6,9 & 7,26 & $6,0-9,0$ \\
\hline OD (mg/L) & 6,04 & 8,35 & 6,43 & 3,22 & 4,36 & 7,12 & $\geq 6$ \\
\hline $\begin{array}{c}\text { Condutividade } \\
(\mu \mathrm{S} / \mathrm{cm})\end{array}$ & 36 & 145,5 & 45,67 & 19 & 149,67 & 54 & - \\
\hline $\begin{array}{c}\text { Sólidos Totais } \\
()\end{array}$ & 18 & 72,5 & 23 & 9,5 & 74,67 & 27 & $\leq 500$ \\
\hline $\begin{array}{c}\text { Turbidez } \\
(\text { UNT) }\end{array}$ & 34,3 & 0,15 & 13,07 & 0,25 & 35,57 & 11,23 & $\leq 40$ \\
\hline $\begin{array}{c}\text { Temperatura } \\
\left({ }^{\circ} \mathrm{C}\right)\end{array}$ & 21 & 23,8 & 22,8 & 26,4 & 26,6 & 20,8 & $\leq 40$ \\
\hline
\end{tabular}

Fonte: Autores (2017), adaptação CONAMA 357/2005

Todos os parâmetros foram analisados de acordo com a resolução CONAMA $357 / 2005$, exceto a temperatura, a condutividade e o potencial de oxirredução, pois são parâmetros que estão relacionados com outros parâmetros na avaliação da qualidade da água, não especificando valores máximos para estes na legislação. Com a análise dos dados obtidos, observa-se que para o assentamento Emiliano Zapata os pontos 1, 2 e 5, encontram-se com pH abaixo da faixa estipulada pela resolução CONAMA 357 de 2005, e no Nova Tangará assentamento apenas os pontos 1 e 4 estão abaixo dos valores estabelecidos estão em conformidade com a legislação. De acordo com Vasconcelos (2012), o parâmetro pH pode ser influenciado pela quantidade de matéria morta a ser decomposta, pois para que haja a decomposição dessa matéria é necessária a produção de ácidos, assim quanto maior a quantidade de matéria orgânica disponível, menor o pH. Portanto, o baixo valor encontrado para os assentamentos podem indicar uma alta quantidade de matéria orgânica. 


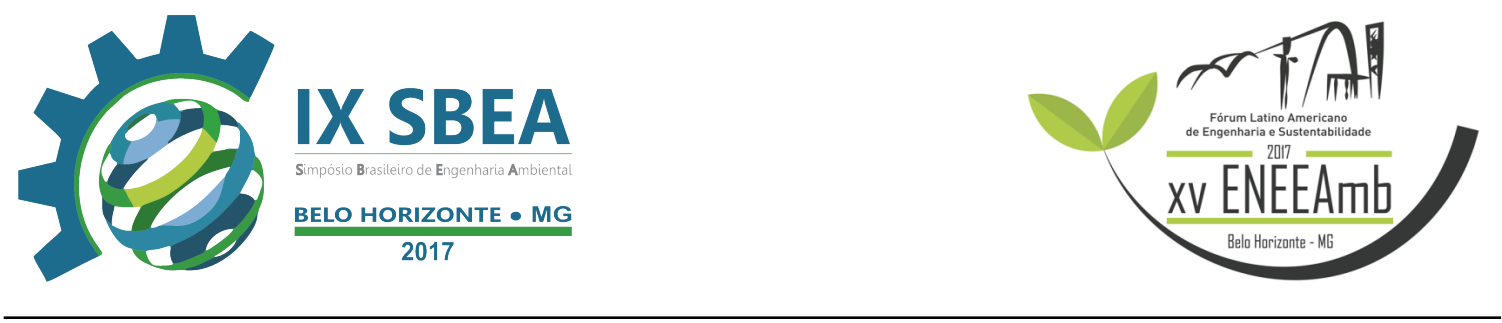

Conforme observado na tabela 2, para os pontos analisados, o oxigênio dissolvido apresentou valores acima do mínimo permitido, indicando assim que a água pode estar apta para consumo humano. Já para o assentamento Nova Tangará os valores do ponto 4 e 5 foram abaixo dos valores estabelecidos pela resolução. Além disto, os valores para a turbidez estão dentro dos parâmetros estipulados que regem turbidez menor ou igual a 40 UNT tanto para o Assentamento Emiliano Zapata quanto para o Nova Tangará.

Apesar da temperatura não ser um parâmetro determinado pela resolução $357 / 2005$, esta é um fator preponderante quando relacionada a outros parâmetros, pois Segundo Queiroz (2003), a temperatura da água é um dos parâmetros físicos mais importantes para o estudo dos ecossistemas aquáticos, pois ela interfere diretamente nos processos metabólicos vitais, tais como a respiração, a solubilidade dos gases dissolvidos como o oxigênio e na densidade da água que influencia na mistura e movimentos das massas de água. A condutividade não é determinada pela resolução CONAMA 357/2005. Fravet e Cruz (2007) explicam que a condutividade depende das concentrações iônicas e da temperatura, pois estas indicam a quantidade de sais existentes na coluna d'água, sendo um cálculo indireto da concentração de poluentes. Para os autores, valor superior a $100 \mu \mathrm{S} / \mathrm{cm}$ indica ambientes impactados. Os sólidos dissolvidos totais, apresentaram-se de acordo com a norma tanto para o Assentamento Emiliano Zapata quanto para o Nova Tangará. O último parâmetro que não possui valores determinados pela legislação é o potencial de oxirredução.

\section{CONCLUSÕES/RECOMENDAÇÕES}

A partir das análises realizadas, observou-se que os valores da concentração para as amostras do Assentamento Emiliano Zapata e do Assentamento Nova Tangará estão dentro do permitido, segundo os padrões estabelecidos pela CONAMA No 357/2005.

Por fim, ações como análises periódicas da qualidade da água na comunidade, bem como o tratamento, limpeza e manutenção das caixas da água da população, são necessárias para melhoria do saneamento básicos destas famílias e, consequentemente, melhoria na saúde da população. A gestão deste recurso deve ser pensada de maneira a 


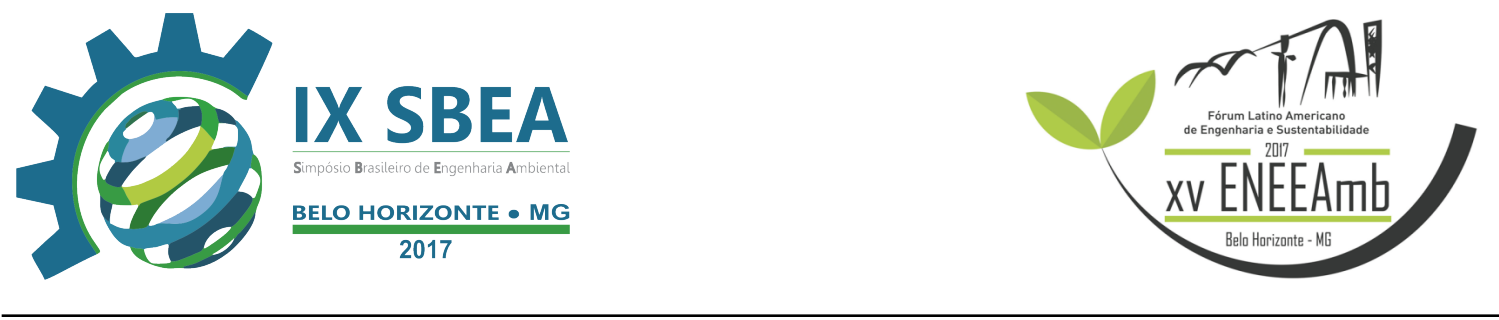

racionalizar seu consumo, promover estratégias de reuso, e tecnologias voltadas para os pequenos produtores, que utilizam a água indiretamente no sustento de suas famílias e, portanto, necessitam de água de qualidade.

\section{REFERÊNCIAS BIBLIOGRÁFICAS}

ALMEIDA, A. Movimentos sociais e políticas de reforma agrária no Brasil. Conquistas e percalços dos trabalhadores na luta pela terra. Uberlândia, 16p. (Inédito, $\mathrm{s} / \mathrm{d})$.

Brasil. Fundação Nacional de Saúde (FUNASA). Manual de saneamento. 3. ed. rev. Brasília: Fundação Nacional de Saúde, 2004. 408 p. Disponível em: $<$ http://www.sebrae.com.br/customizado/gestao-

ambientalbiblioteca/bib_manual_saneamento.pdf> Acesso em: 02/2014.

BRASIL. Lei no 11.445 de 5 de janeiro de 2007. Estabelece diretrizes nacionais para o saneamento básico e para a política federal de saneamento básico. Diário Oficial da República Federativa do Brasil, Brasília.CANUTO. J. C.; ÁVILA P. C.; CAMARGO R. C. R. Assentamentos Rurais Sustentáveis: o processo de construção participativa do conhecimento agroecológico e o monitoramento de unidade de referência no Assentamento Sepé Tiaraju-SP. Embrapa Meio Ambiente, Jaguariúna, SP. 2013. Disponível em: <http://www.sigam.ambiente.sp.gov.br/sigam2/repositorio/259/documentos/doc93.pdf> Acesso em 10/2014.

LAMPARELLI , M. C. Grau de trofia em corpos d'água do estado de São Paulo: avaliação dos métodos de monitoramento. São Paulo: USP/ Departamento de Ecologia, 2004. 235 f. Tese de doutorado, Universidade de São Paulo, 2004.

MARTINS, JOSÉ DE S. O Sujeito Oculto: Ordem e transgressão na reforma agrária. Editora Universidade Federal do Rio Grande do Sul. Porto Alegre, 2003.

Portaria de Potabilidade N² 2.914 de 12 de dezembro de 2011. Ministério da Saúde.

Resolução CONAMA no 357, de 17 de Março 2005. Estabelece a classificação de águas doces, salobras e salinas. Diário Oficial da República Federativa do Brasil, Brasília.

Resolução CONAMA no 387, de 27 de Dezembro de 2006. Estabelece procedimentos para o Licenciamento Ambiental de Projetos de Assentamentos de Reforma Agrária, e dá outras providências. Diário Oficial da República Federativa do Brasil, Brasília.

STUKEL, T. A.; GREENBERG, E. R.; DAIN, B. J.; REED, F. C.; JACOBS, N. J. A longitudinal study of rainfall and coliform contamination in small community drinking water supplies. EnvironSciTechnol, 1990. 